Article

\title{
Assessing the Potential of Co-Pt Bronze for Electrocatalysis in Acidic Media
}

\author{
Yuji Kamitaka ${ }^{1}$ (D), Noboru Taguchi ${ }^{2}$ and Yu Morimoto ${ }^{1, *(D)}$ \\ 1 Toyota Central R\&D Labs., Inc., Aichi 480-1192, Japan; kamitaka@mosk.tytlabs.co.jp \\ 2 National Institute of Advanced Industrial Science and Technology, Osaka 563-8577, Japan; \\ n-taguchi@aist.go.jp \\ * Correspondence: morimoto@mosk.tytlabs.co.jp; Tel.: +81-561-71-7207
}

Received: 6 June 2018; Accepted: 21 June 2018; Published: 25 June 2018

\begin{abstract}
An electron-conducting mixed oxide, Co-Pt bronze was synthesized and examined as a candidate for a highly durable electrocatalyst for both the polymer electrolyte fuel cells and electrolyzers. The motivation of this study comes from the fact that this material has not been studied as an electrocatalyst in acidic media, although past studies showed a high electronic conductivity and a high corrosion resistance. Co-Pt bronze without metallic Pt was obtained by solid-state synthesis and hot aqua regia rinsing. The OER activity was found to be among the highest as a material without Ir and Ru in acidic media, and it showed extremely high electrochemical stability in the OER potential range. Its oxygen reduction reaction (ORR) was obtained after potential cycles down to the hydrogen region, which formed a thin Pt metallic layer over the oxide. While its specific activity was not more than that of pure platinum nanoparticles, its durability against the potential cycles was much higher.
\end{abstract}

Keywords: polymer electrolyte fuel cells; oxygen reduction reaction catalyst; polymer electrolyte water electrolysis; oxygen evolution reaction catalysts; mixed oxide

\section{Introduction}

Electrocatalysts facilitating electrochemical reactions are one of the most important components for realizing the hydrogen economy. In PEFCs, metallic platinum is mostly used for both the anode and cathode. While platinum is highly active in hydrogen oxidation reactions (HORs), its activity toward oxygen reduction reactions (ORR) is not sufficiently high for wider commercialization; therefore, various attempts have been made to enhance activity by alloying [1], forming core-shell structures [2] and shape-controlling [3,4]. Generally speaking however, active samples show poor durability, while durable samples show lower activity [5]. In practical usage, high activity without high durability is virtually useless; however, unlike the cases for activity improvement described above, no clear strategies have been proposed for durability improvement. In practical PEFC operation, other degradation modes were identified with regard to the electrocatalysts. One of those modes is called as the start-up/shut-down reverse current mode [6], in which an areal part is in $\mathrm{H}_{2}$ / Air condition while others are in Air/Air condition. In this mode, the electromotive force in the $\mathrm{H}_{2}$ / Air area causes a carbon oxidation reaction on the "cathode" (the air side electrode in the normal operation). To alleviate this mode of degradation, a high oxygen evolution reaction (OER) activity should be provided to the "cathode". Another degradation mode is called the reverse potential mode [7], in which if insufficient $\mathrm{H}_{2}$ gas, compared to applied current, is supplied to some cells in a series connected stack, the potential is reversed to cause carbon oxidation in the anode. In this mode, again, a high OER activity should be provided to the anode. In both degradation modes, the key is the high OER activity.

In water electrolysis, platinum is sufficiently active for hydrogen evolution reactions (HERs), but not for oxygen evolution reaction (OER). While various nonprecious metals can be used as OER 
catalysts for alkali electrolysis [8], only precious metals can be used for acidic polymer electrolyte membrane electrolysis, which allows much higher current density compared to alkali electrolysis, and therefore, arguably lower overall cost for hydrogen production. Among the OER catalysts in acidic media, iridium and/or ruthenium (mixed) oxides are regarded as the most active [9-11]. For stabilities, ruthenium metal and oxides are regarded as unstable, since ruthenium forms volatile $\mathrm{RuO}_{4}$. Iridium, in contrast, does not form a volatile product, but can be dissolved as an ion, especially when the catalyst is electrochemically redoxable $\operatorname{IrO}_{x}(x<4)$, which is more OER active [12]. Moreover, those two elements are among the scarcest (much scarcer than platinum) [13], and their usage will be an obstacle for wide distribution of water electrolyzers. Therefore, electrocatalysts without these two elements should be developed.

Another electrochemical device relating electrocatalysts and hydrogen is a reversible fuel cell, which operates as a fuel cell when electricity is necessary, and also as an electrolyzer when electricity is redundant. Reversible fuel cells are, if realized, as advantageous as a renewable energy system, since separate systems of fuel cells and electrolyzers are no longer necessary. In this application, however, an electrocatalyst that is active for both OER and ORR is required, since no such material is available [14].

Recently, we have started to study metal-platinum oxide bronzes (Figure 1, crystalline structure of Co-Pt bronze) as multi-purpose electrocatalysts for ORR, OER, HOR, and HER. From the late 1970s to early 1990s, platinum oxide bronzes of the type of $\mathrm{M}_{\mathrm{x}} \mathrm{Pt}_{3} \mathrm{O}_{4}$, where $\mathrm{M}$ can be $\mathrm{Li}, \mathrm{Na}, \mathrm{Mg}$, $\mathrm{Cs}, \mathrm{Zn}, \mathrm{Cd}, \mathrm{Co}, \mathrm{Ni}$, etc., were synthesized and explored as electrocatalysts for mainly reversible fuel cells in alkali solution [15-18] and limitedly in acidic media $[19,20]$. Since then, however, further studies aiming at polymer electrolyte fuel cells and electrolysis have not been conducted. Although early studies did not exhibit high ORR activities [20], their significantly high anti-oxidation resistance (hot aqua regia resistant), electron conducting property, and non-use of the scarcest elements have attracted our attention, and we have decided to explore their potential as electrocatalysts. In this study, we synthesized Co-Pt bronze and conducted various characterization and electrochemical property examinations including ORR, OER, HER, and HOR activity, and durability tests to clarify whether this type of material has a potential as a practical electrocatalyst in acidic media and is worth further study. Note that this material, in which both $\mathrm{Co}$ and Pt are in their oxidized states, is totally different from Pt-Co alloy catalysts, in which both $\mathrm{Co}$ and $\mathrm{Pt}$ are in their metallic states, and which are known as being among the most active ORR catalyst systems [21-23].

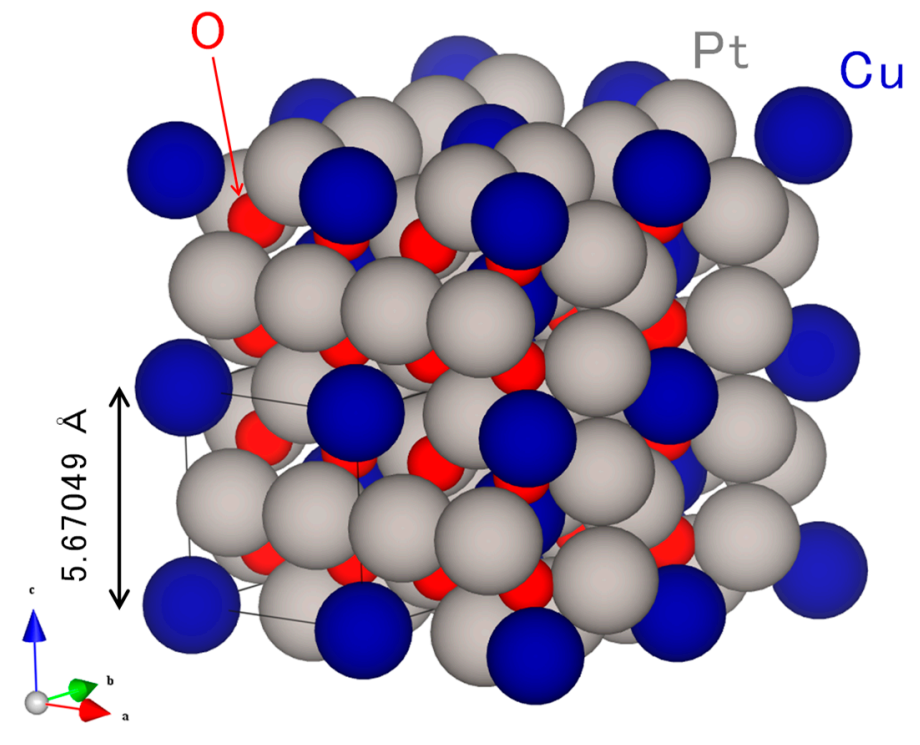

Figure 1. Crystalline structure of Co Pt bronze. 


\section{Results and Discussion}

\subsection{Original Co-Pt Bronze}

\subsubsection{Characterization}

XRD patterns of Co-Pt bronze before and after the hot aqua regia treatment are shown in Figure 2. Before the treatment, peaks assigned to Co-Pt bronze and $\mathrm{Pt}$ metal are clearly seen, but the peak for $\mathrm{Pt}$ metal disappears after the treatment. This analysis indicates that metallic platinum was formed by the synthesis, but removed by the hot aqua regia, and that the final product is Co-Pt bronze only.

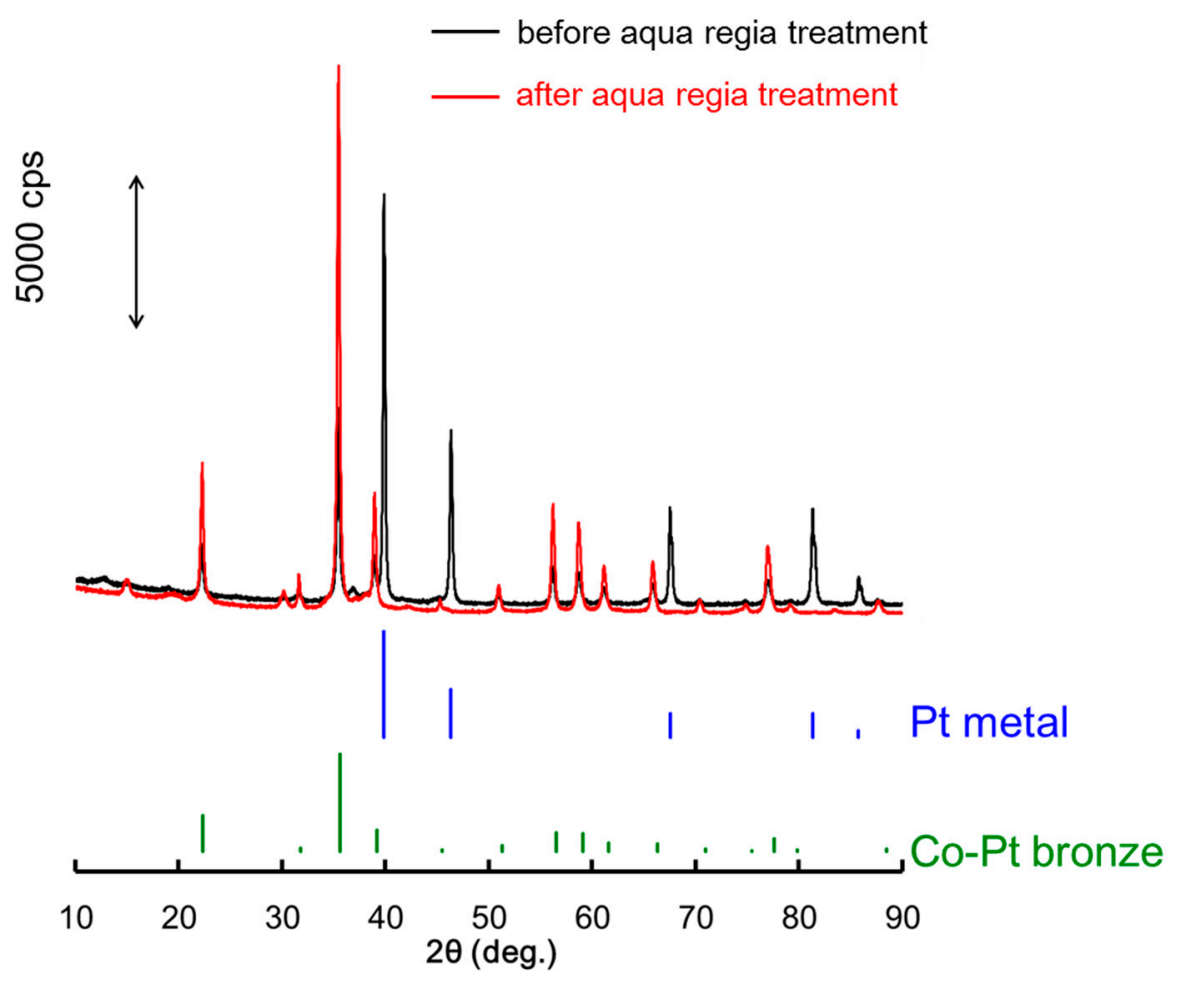

Figure 2. XRD Patterns for Co-Pt bronze before and after aqua regia treatment. Co-Pt bronze peaks were assigned using Rietveld refinement with structural data for $\mathrm{CaPt}_{3} \mathrm{O}_{4}$ : PDF\#04-002-4036 and $\mathrm{CdPt}_{3} \mathrm{O}_{4}$ : PDF\#04-002-4050.

TEM images and EDS mappings of Co-Pt bronze before and after the hot aqua regia treatment are shown in Figure 3. The particle size is $20-50 \mathrm{~nm}$, which roughly agrees with the diameter $(24.6 \mathrm{~nm})$ estimated by BET surface area analysis. EDS mappings show that intense Pt regions existing before the hot aqua regia treatment disappear afterwards. This is another indication of the removal of the Pt metal phase. In addition, spots having strong Co signals exist before the aqua regia treatment, and disappear afterwards. Therefore, unreacted Co content is considered to remain before the treatment and to be removed by it.

Figure 4 shows an electronic conductivity comparison among the Co-Pt bronze (after the hot aqua regia treatment), Vulcan $\mathrm{XC}-72, \mathrm{IrO}_{2}$ (Furuya) and $\mathrm{PtO}_{2}$. At low pressure, conductivities are controlled by particle contact. Increasing pressure, however, decreases the contact resistance and reveals their bulk properties. The trend and absolute value for Vulcan agree well with published data [24]. Unlike $\mathrm{PtO}_{2}$, which is an insulator, Co-Pt bronze shows a high electrical conductivity comparable with Vulcan XC-72 and $\mathrm{IrO}_{2}$. This property is crucial for a good electrocatalyst, especially aiming at devices operating at a high current density, including automotive PEFCs and water electrolyzers. 


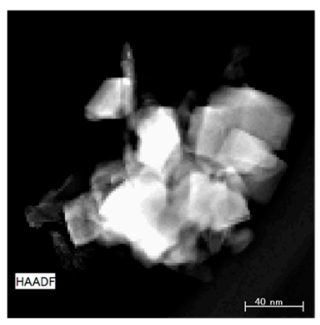

\begin{tabular}{|l|l|l|}
\hline$a$ & $b$ & $c$ \\
\hline$d$ & $e$ \\
\hline
\end{tabular}

(A)before aqua regia
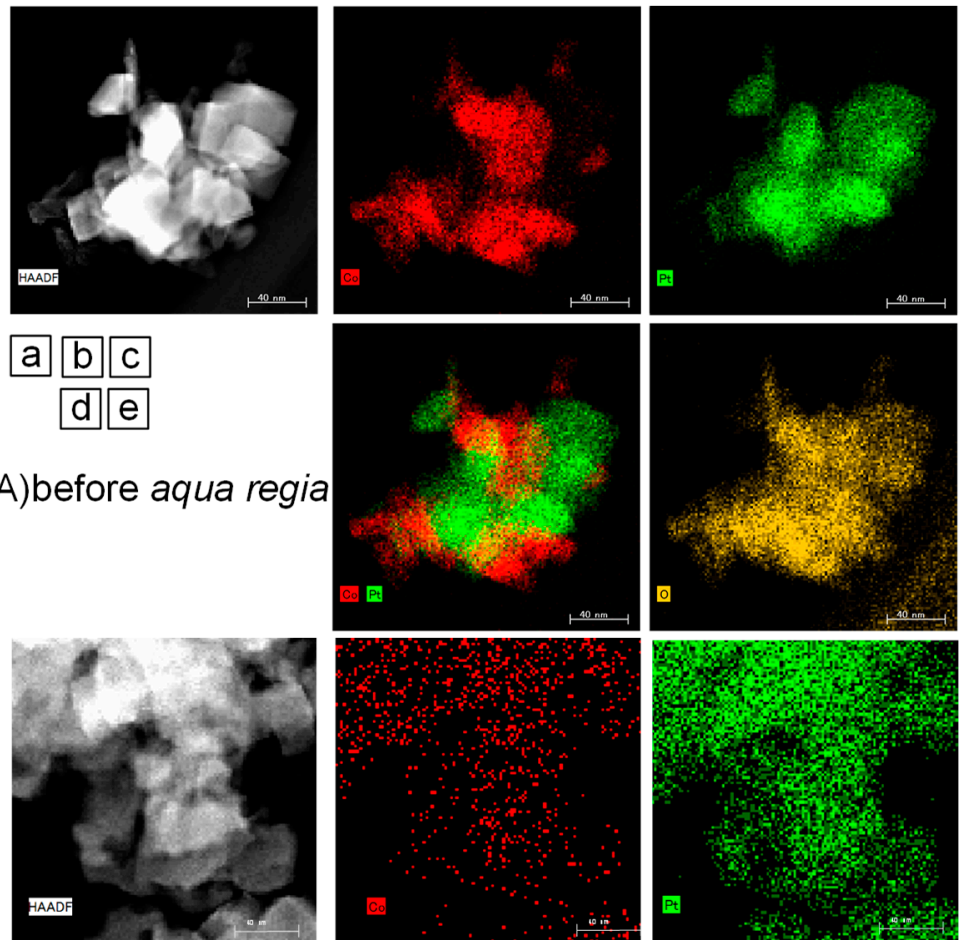

$a$ b $c$ d $\mathrm{e}$

(B)after aqua regia
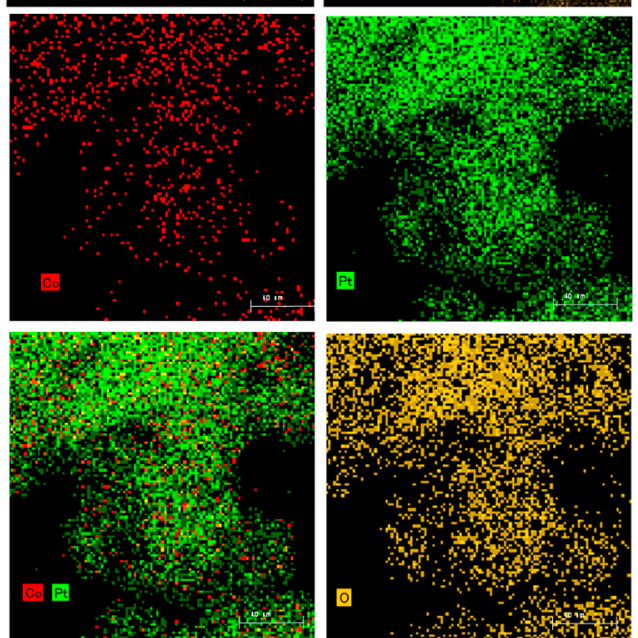

Figure 3. TEM images EDS mapping of Co-Pt bronze (A) before and (B) after aqua regia treatment. (a) HAADF image, (b) $\mathrm{Co}$, (c) Pt, (d) Co and $\mathrm{Pt}$, and (e) O mappings.

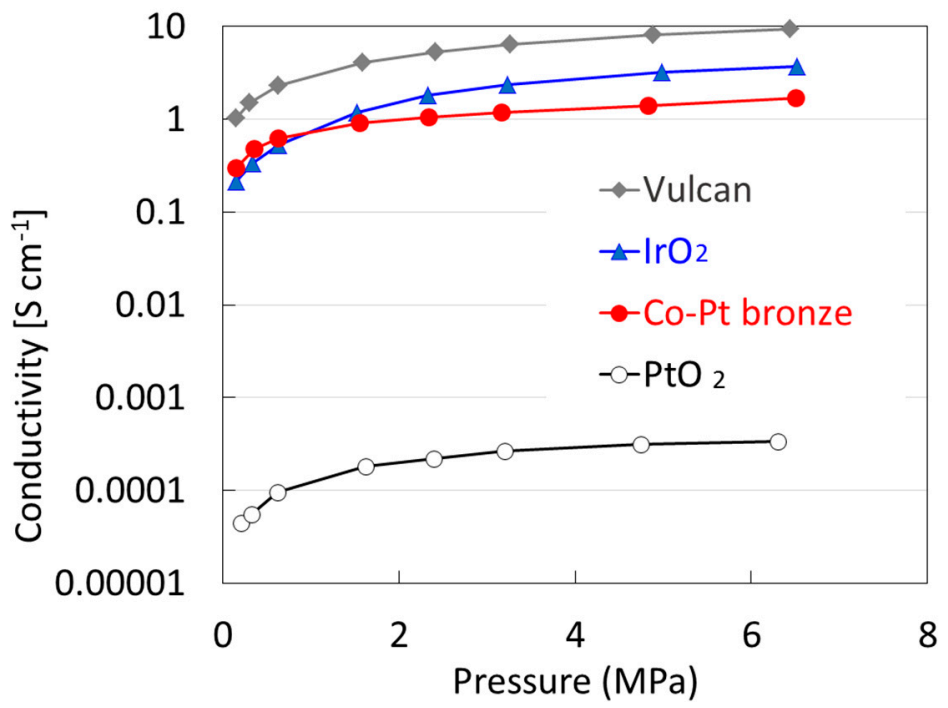

Figure 4. Electronic conductivities of Vulcan (carbon black), $\mathrm{IrO}_{2}$ (Furuya), Co-Pt bronze and $\mathrm{PtO}_{2}$ measured by a compression cell. 


\subsubsection{Electrochemical Properties}

OER activities were measured by potential sweep and potential holding, as shown in Figure 5a,b, respectively, as current density per BET surface area. The specifications and OER activities of tested catalysts are listed in Tables 1 and 2, respectively. Although Pt black initially showed a comparable activity, that activity quickly faded because $\mathrm{PtO}_{2}$, an insulator, grew on the surface. Two iridium oxides showed significantly different behaviors. $\mathrm{IrO}_{2}$ (Alfa Aesar) showed larger hysteresis in the voltammogram and maximum current of the potentiostat for initial ca. $10 \mathrm{~s}$ after the potential step from 0.4 to $1.7 \mathrm{~V}$. Those observations are most likely due to a redox reaction of $\mathrm{IrO}_{2}$ (Alfa Aesar), since the XRD pattern shown in Figure S1 shows that $\mathrm{IrO}_{2}$ (Alfa Aesar) is actually a mixture of crystalline iridium metal and amorphous-like iridium oxide, both of which (or at least iridium metal) can be electrochemically active. In contrast, $\mathrm{IrO}_{2}$ (Furuya) showed no hysteresis in the voltammogram, and reached the steady-state current instantly after the potential step, suggesting that crystalline $\mathrm{IrO}_{2}$, such as $\mathrm{IrO}_{2}$ (Furuya) as shown in Figure S1, is electrochemically stable. The higher activity of $\mathrm{IrO}_{2}$ (Alfa Aesar) compared to $\mathrm{IrO}_{2}$ (Furuya) may stem from the presence of lower valent iridium, since $\operatorname{Ir}(\mathrm{III})$ is considered more active than $\operatorname{Ir}(\mathrm{IV})$ [12] for OER. Against potential cycles, however, catalysts containing $\operatorname{Ir}(\mathrm{III})$ are generally regarded as being less stable [12], although that trend is not seen in this short potential holding test.

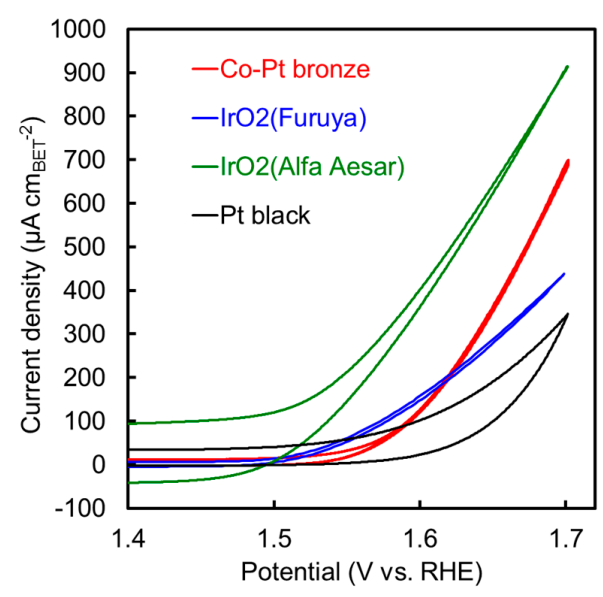

(a)

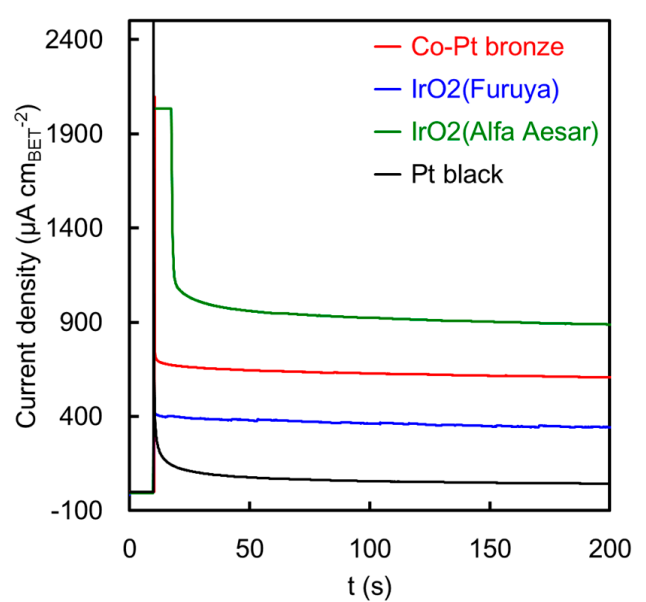

(b)

Figure 5. OER activity measurement results, (a) potential sweep and (b) Potential hold at 1.7 V (vs. RHE).

Table 1. Specifications of tested OER catalysts.

\begin{tabular}{lcccc}
\hline & $\begin{array}{c}\text { Specific Surface Area } \\
(\mathbf{B E T})\end{array}$ & $\begin{array}{c}\text { Mean Diameter } \\
\left(\mathbf{m}^{\mathbf{2}} \cdot \mathbf{g}^{\mathbf{- 1}}\right)\end{array}$ & $\begin{array}{c}\text { Loading/GC }(\boldsymbol{\mu g}) \\
(\mathbf{n m})\end{array}$ & $\begin{array}{c}\text { Loaded Surface } \\
\text { Area/GC }\left(\mathbf{c m}^{\mathbf{2}}\right)\end{array}$ \\
\hline Co-Pt bronze & 19 & 25 & 16 & 2.9 \\
Pt black & 13 & 22 & 11 & 1.4 \\
$\mathrm{IrO}_{2}$ (Furuya) & 54 & 9.6 & 13 & 7.2 \\
$\mathrm{IrO}_{2}$ (Alfa & 34 & 15 & 16 & 5.4 \\
Aesar) & 34 & & \\
\hline
\end{tabular}

* Mean diameter was calculated from BET surface area assuming monodispersed spherical particles with bulk density of respective material as: $D(\mathrm{~nm})=6000 /\left\{\operatorname{BET}\left(\mathrm{m}^{2} / \mathrm{g}\right)^{*} \cdot \rho\left(\mathrm{g} / \mathrm{cm}^{3}\right)\right\}$.

Co-Pt bronze showed no hysteresis in the voltammograms, and exhibited stable OER currents, just like $\mathrm{IrO}_{2}$ (Furuya). These results also suggest that Co-Pt bronze can be an extremely stable OER catalyst. Its OER activity is lower than that of $\mathrm{IrO}_{2}$ below $1.62 \mathrm{~V}$, but higher than that of $\mathrm{IrO}_{2}$ (Furuya) over 1.6 V. Activities at higher potential with higher current, however, are affected by the conductivity 
of powders, especially under RDE condition, since powders are not compressed and smaller powders tend to exhibit lower conductivity by contact resistance.

OER activities are also compared with published data [10,11] using $\mathrm{IrO}_{2}(\mathrm{Alfa}$ Aesar) in Table 2. $\mathrm{IrO}_{2}$ (Alfa Aesar) of this work showed lower OER activity than $\mathrm{IrO}_{2}$ (Alfa Aesar) of published data $[10,11]$, especially at $1.60 \mathrm{~V}$. This difference could be due to difference in experimental conditions (e.g., IR-corrected $[10,11]$ vs. not corrected in this work), or the difference in thin film formation (e.g., with Nafion $[10,11]$ vs. without it in this work). In this screening study, which aims to reveal the potential of Pt-Co bronze as an electrocatalyst, further analyses were not carried out.

Table 2. OER activity comparison.

\begin{tabular}{|c|c|c|c|c|c|}
\hline & $\begin{array}{c}\text { Specific } \\
\text { Surface Area } \\
\left(\mathrm{m}^{2} \mathrm{~g}^{-1}\right)\end{array}$ & $\begin{array}{c}\text { Specific } \\
\text { Activity@1.55 } \\
\mathrm{V}\left(\mu \mathrm{A} \mathrm{cm}{ }^{-2}\right)\end{array}$ & $\begin{array}{c}\text { Mass } \\
\text { Activity@1.55 } \\
\left.\text { V (A } \text { g }_{\text {PGM }}{ }^{-1}\right)\end{array}$ & $\begin{array}{c}\text { Specific } \\
\text { Activity@1.60 } \\
\mathrm{V}\left(\mu \mathrm{A} \mathrm{cm}{ }^{-2}\right)\end{array}$ & $\begin{array}{c}\text { Mass } \\
\text { Activity@1.60 } \\
\left.\text { V (A } \text { g }_{\text {PGM }}{ }^{-1}\right)\end{array}$ \\
\hline Co-Pt bronze & $19 * 1$ & 31 & 7.8 & 125 & 31 \\
\hline $\mathrm{IrO}_{2}$ (Furuya) & $54 * 1$ & 61 & 38 & 158 & 98 \\
\hline $\mathrm{IrO}_{2}$ (Alfa Aesar) This work & $34 * 1$ & 212 & 85 & 402 & 161 \\
\hline $\mathrm{IrO}_{2}$ (Alfa Aesar $\left.[10,11]\right)$ & $28.7 * 2$ & 480 & 138 & 2536 & 729 \\
\hline
\end{tabular}

${ }^{* 1}$ : BET surface area per unit weight; ${ }^{* 2}$ : electrochemical surface area per unit weight of iridium.

Longer durability tests, which are necessary for practical purposes, are desirable but were not carried out because powder catalysts deposited on glassy carbon used in this experiment (no ionomer added as a binder) were easily detached from glassy carbon by the oxygen evolution, carbon corrosion, and electrolyte turbulence. Longer durability test should be carried out using a membrane electrode assembly, which is only possible after a significant amount of catalysts is synthesized; this is beyond the scope of this paper.

Although the exact comparison of the results from these initial performance and short stability test among these samples is not possible because their surface areas and morphologies were not uniformly controlled (see Table 1), it is still safe to judge that Co-Pt bronze has a similar OER activity and durability with crystalline $\mathrm{IrO}_{2}$. These classes of catalysts have a great potential as OER catalysts without $\mathrm{Ir}$ and $\mathrm{Ru}$, which should be further explored in future studies.

Voltammograms under argon and oxygen atmospheres are compared in Figure 6 to examine the ORR activity. Current below $0.8 \mathrm{~V}$ under oxygen atmosphere is clearly the ORR current, while current at $0.9 \mathrm{~V}$, which is a standard potential to define the activity for Pt metal based catalyst, is negligible. This low activity agrees well with a previous study [15]. Therefore, the intrinsic ORR activity is very limited, but as the following section shows, potential cycles to the hydrogen potential regions can provide a significant increase in ORR activity, which makes this material attractive for reversible fuel cells.

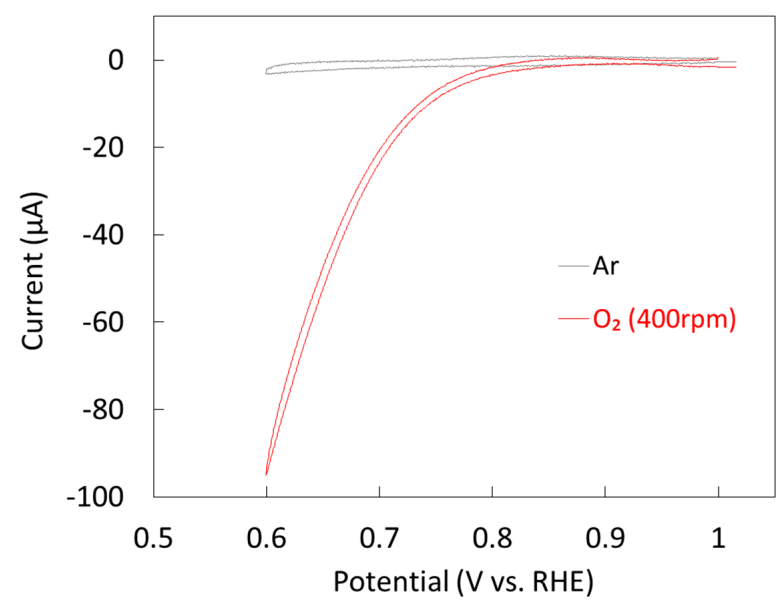

Figure 6. ORR activity measurement voltammogram for original Co-Pt Bronze. 


\subsection{Surface Treated Co-Pt Bronze}

The surface of the original Co-Pt bronze was electrochemically activated by potential cycles between 0.05 and $1.2 \mathrm{~V}$ vs. RHE under inert conditions. Voltammograms during these cycles are shown in Figure 7. As the number of cycles increases, typical voltammetric features of Pt metal emerge. After 100 cycles, the voltammogram becomes like that of Pt metal, and no further change was observed after 100 cycles. The platinum metal electrochemical surface area was calculated from the hydrogen desorption charge using a commonly used conversion factor of 210 microCoulomb $/ \mathrm{cm}^{2}$, and the Pt metal coverage was obtained by dividing the electrochemical surface area by the BET surface area of loaded powder as 0.15 . Therefore, roughly $15 \%$ of Pt-Co bronze was estimated to be reduced and covered with metallic platinum.

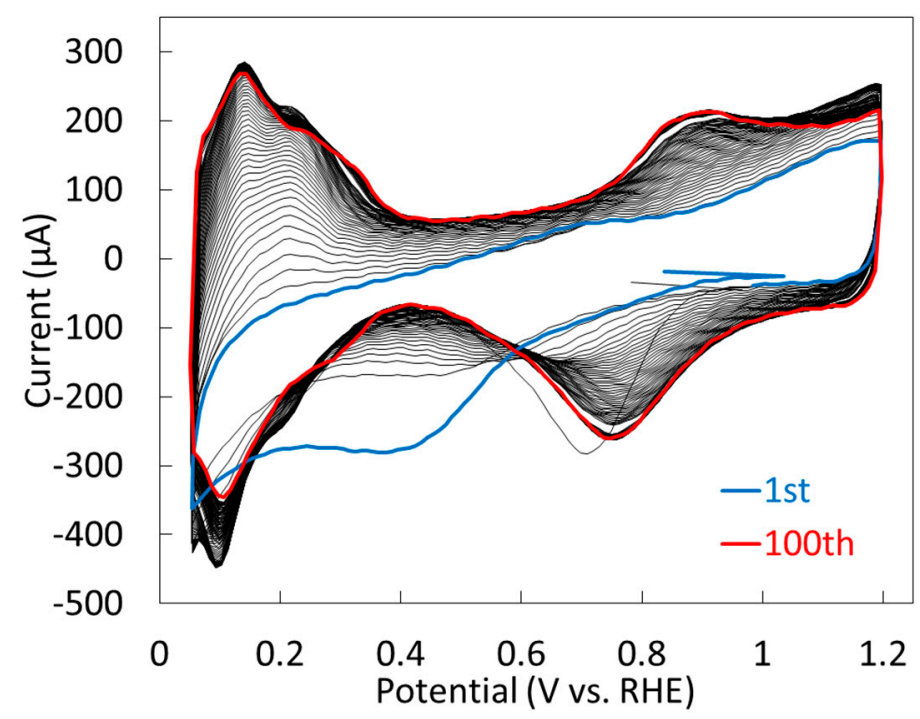

Figure 7. Cyclic voltammograms during activation potential cycles. 1st and 100th cycles are highlighted.

\subsubsection{Characterization}

Figure 8 shows Pt $4 \mathrm{f}$ XPS spectra of the Co-Pt bronze before and after the potential cycles. Although two major peaks (Pt4f7/2: ca. $72 \mathrm{eV}$ and Pt4f5/2: ca. $76 \mathrm{eV}$ ) corresponding to $\mathrm{Pt}(\mathrm{I})$ or (II) are unchanged, after the potential cycles, a peak (ca. $78 \mathrm{eV}$ ) corresponding to $\mathrm{Pt}(\mathrm{IV})$ disappears and a shoulder (ca. $71 \mathrm{eV}$ ) corresponding to Pt metal appears. Figure 9 shows XRD patterns of Co-Pt bronze loaded on glassy carbon after the potential cycles, which exhibits peaks of the bronze only but no Pt metal. These data, combined with CV patterns, suggest that the potential cycles induced formation of a Pt metal film that locates only on the surface of the Co-Pt bronze, and is thin enough not to be detected by XRD. This suggestion is confirmed by TEM observation and EDS analysis, shown in Figure 10. The TEM image shows, on a plate-like substrate, numerous bright flat areas $(<10 \mathrm{~nm})$, which were not observed before the potential cycles (Figure 3B), and which can be regarded as formed Pt metallic films. The lower portion of the EDS image exhibits a concentrated Pt area, which seems to correspond to part of the formed Pt metallic film islands. (TEM EDS analysis is not surface-sensitive as XPS.) Further element mapping under high magnitude and elemental point analysis were not carried out because the strong electron beam for those analyses was found to induce reduction reactions of the bronze, and to change the composition and shape during analysis. 


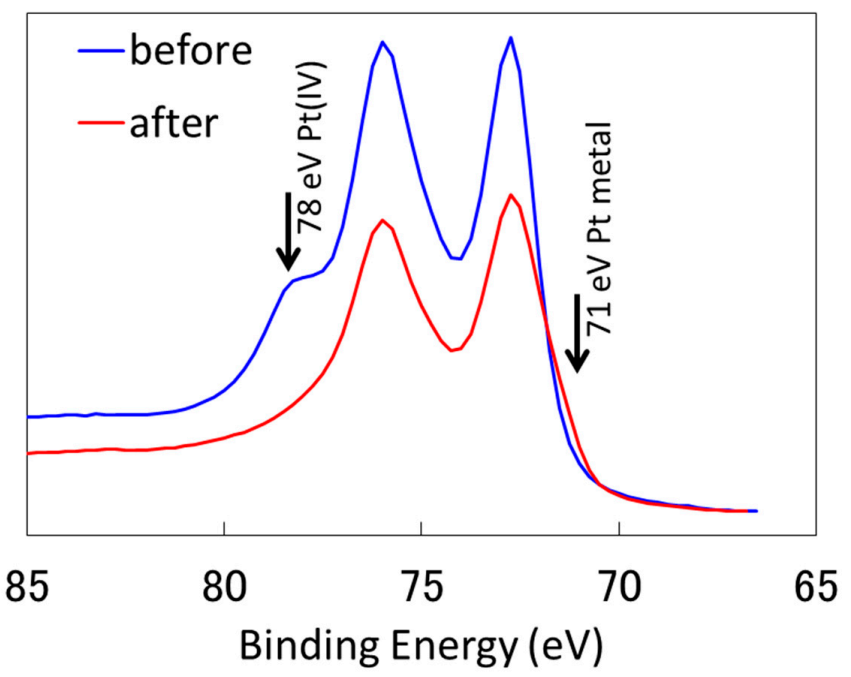

Figure 8. Pt4f5/2 XPS spectra before and after the activation treatment.

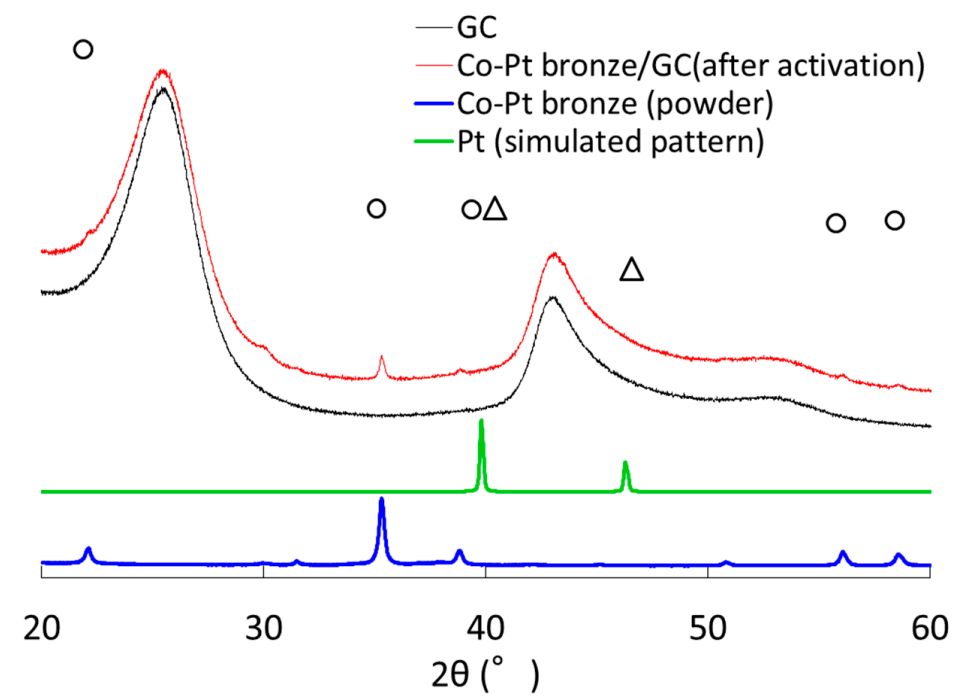

Figure 9. XRD pattern of Co-Pt bronze on glassy carbon after the activation treatment compared with those of Co-Pt bronze powder, glassy carbon and Pt metal.
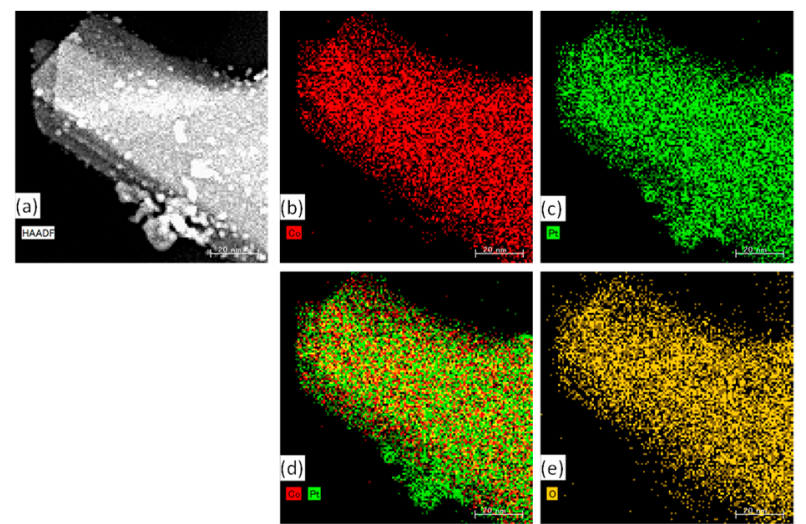

Figure 10. EDS analysis of activated Co-Pt bronze. (a) HAADF; (b) Co; (c) Pt; (d) Co and Pt; and (e) O images. 


\subsubsection{Electrochemical Properties}

Linear sweep voltammograms for ORR examination are shown in Figure 11. The ORR activity is drastically improved after the potential cycles seemingly because of the $\mathrm{Pt}$ thin film formation. The active sites for ORR, therefore, should be the metallic platinum formed by the potential cycles. Figure 12 compared (1) specific surface areas determined by hydrogen desorption charge in Figure 7 and deposited $\mathrm{Pt}$ weight, (2) specific ORR activity determined by ORR current at $0.9 \mathrm{~V}$ and the surface area, and (3) ORR mass activity with those of $\mathrm{Pt} / \mathrm{C}$. Since the Co-Pt bronze has a much larger particle size (24.6 nm vs. $2.4 \mathrm{~nm}$ of $\mathrm{Pt} / \mathrm{C}$ ); its specific surface area is much smaller, resulting in the smaller mass activity. The specific activity, however, is similar with $\mathrm{Pt} / \mathrm{C}$, and no further improvement effects such as the alloying effect observed in Pt-Co alloy systems were observed. However, if a smaller size of Co-Pt bronze is synthesized, the mass activity is expected to significantly improve.

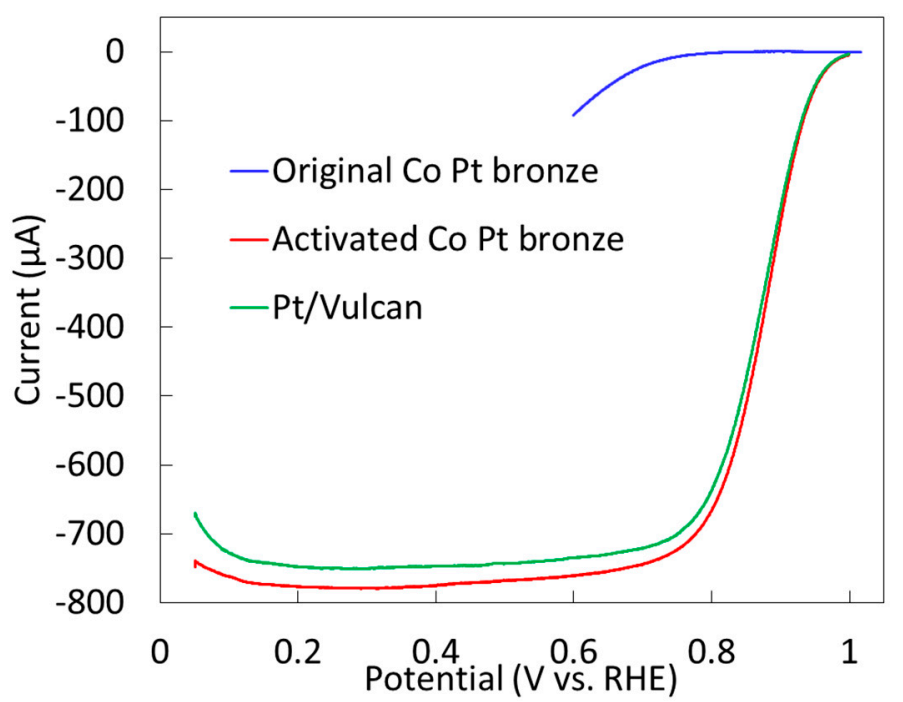

Figure 11. ORR activity measurement voltammogram of activated Co-Pt bronze compared with original Co-Pt bronze and Pt/Vulcan.
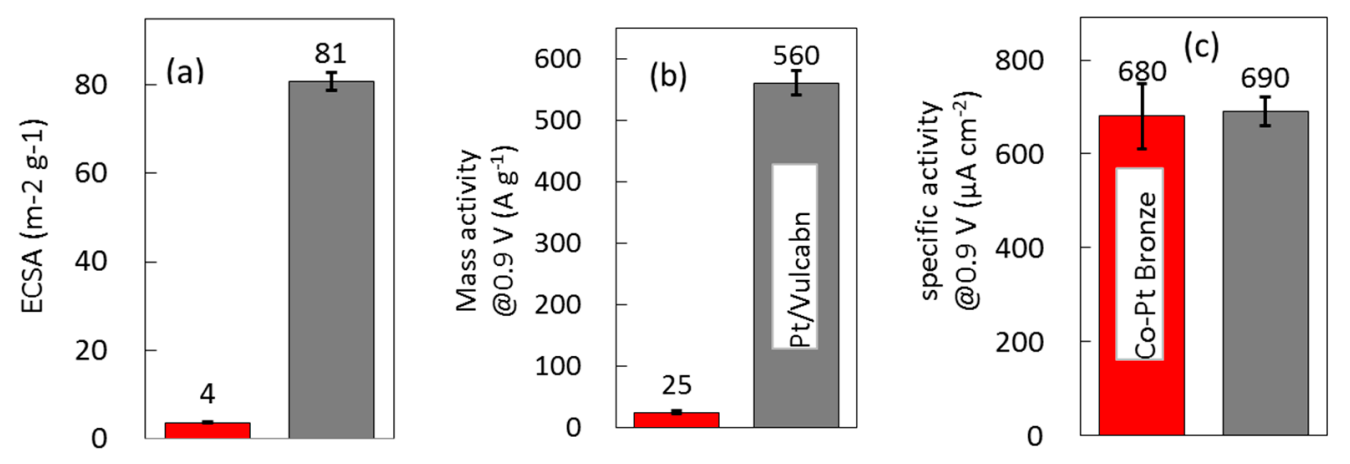

Figure 12. (a) ECSA; (b) ORR mass activity and (c) ORR specific activity comparisons between Co-Pt bronze and $\mathrm{Pt} /$ Vulcan.

Cyclic voltammograms during the ADT are shown in Figure 13 for Pt black, Pt/Vulcan and Co-Pt bronze. Pt black shows only a slight decrease in $\mathrm{H}$-upd area, while Pt/Vulcan shows almost total disappearance in H-upd. Co-Pt bronze also showed a significant decrease, but even after 10,000 cycles, the voltammetric feature of $\mathrm{H}$-upd is still recognizable. ECSAs, which are calculated by deducting double-layer discharge coulombs from $\mathrm{H}$ desorption coulombs, per unit weight of platinum were plotted in Figure 14, as well as their relative values from their initial values. In addition, dissolved $\mathrm{Pt}$ ion amounts in the ADT electrolyte were plotted in Figure 15. The ECSA decrease of Pt-black is 
limited, because it has a large particle size, and new platinum surface would be available even after the surface is dissolved. The ECSA loss of $20 \%$ matched its dissolved portion in the electrolyte. Pt/Vulcan exhibited almost total dissolution and total loss in ECSA, and the remaining ECSAs are probably artefacts from the double layer charge estimation. Co-Pt bronze, having a large particle size and a small portion (15\%) coverage with thin layered Pt metal, shows limited initial ECSA and ca. $60 \%$ loss. The dissolution, however, is very limited (ca. 5\%). This discrepancy of Co-Pt bronze can be elucidated, assuming that the ADT dissolves only the metallic Pt formed by the activation cycles, leaving the bronze phase intact. This assumption was confirmed by TEM observation of the sample after the ADT, which showed no Pt islands anymore, as shown in Figure S3. Then, re-activation cycles were applied on the sample after ADT, as shown in the voltammogram of Figure 16, which clearly shows recovery of Pt metal surface. Although the recovered area is smaller than that shown in Figure 7, this is a remarkable and unique feature as an electrocatalyst for PEFCs.
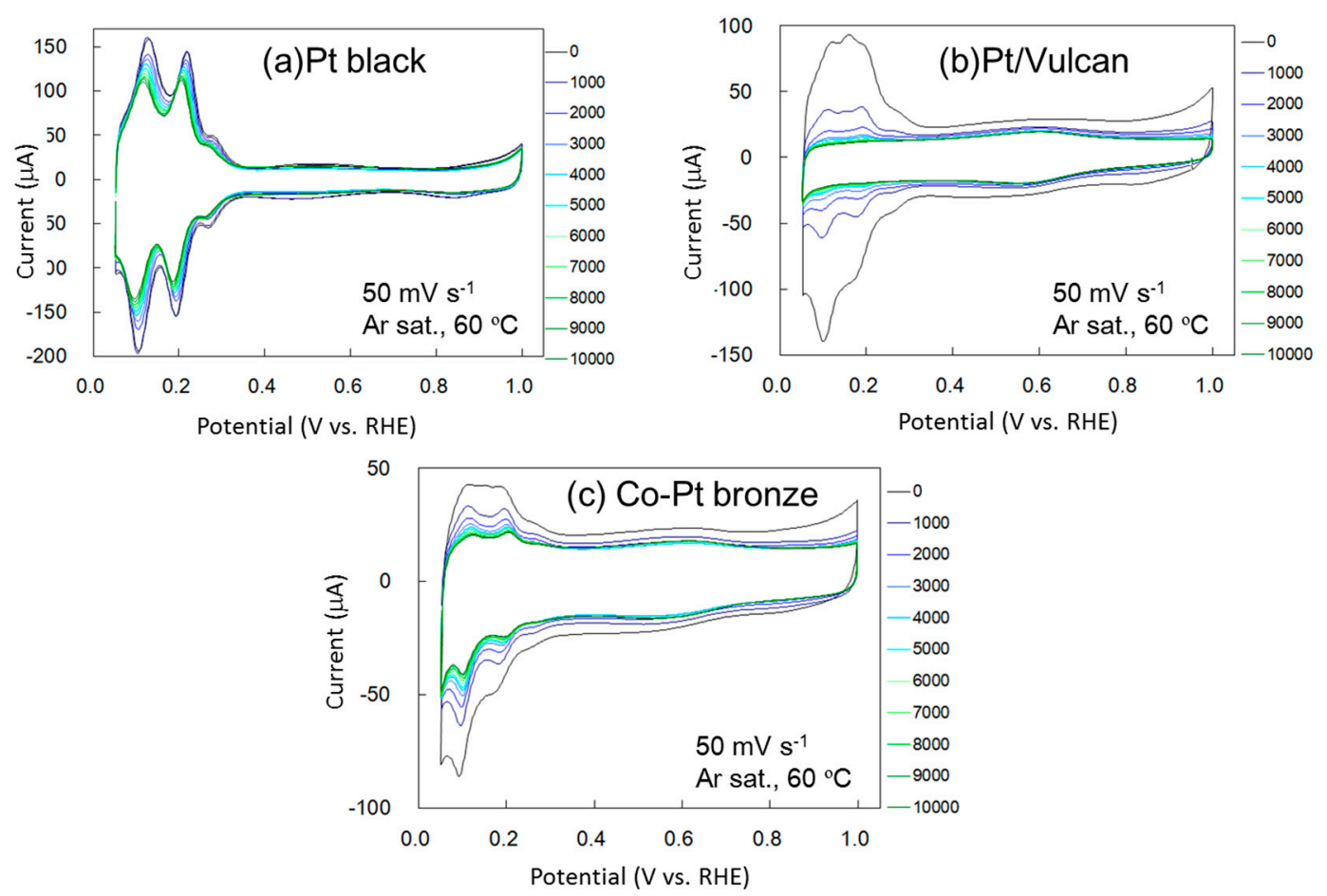

Figure 13. Cyclic voltammograms during the accelerated durability test after 0 to 10,000 cycles. (a) Pt black; (b) Pt/Vulcan and (c) Co-Pt bronze.
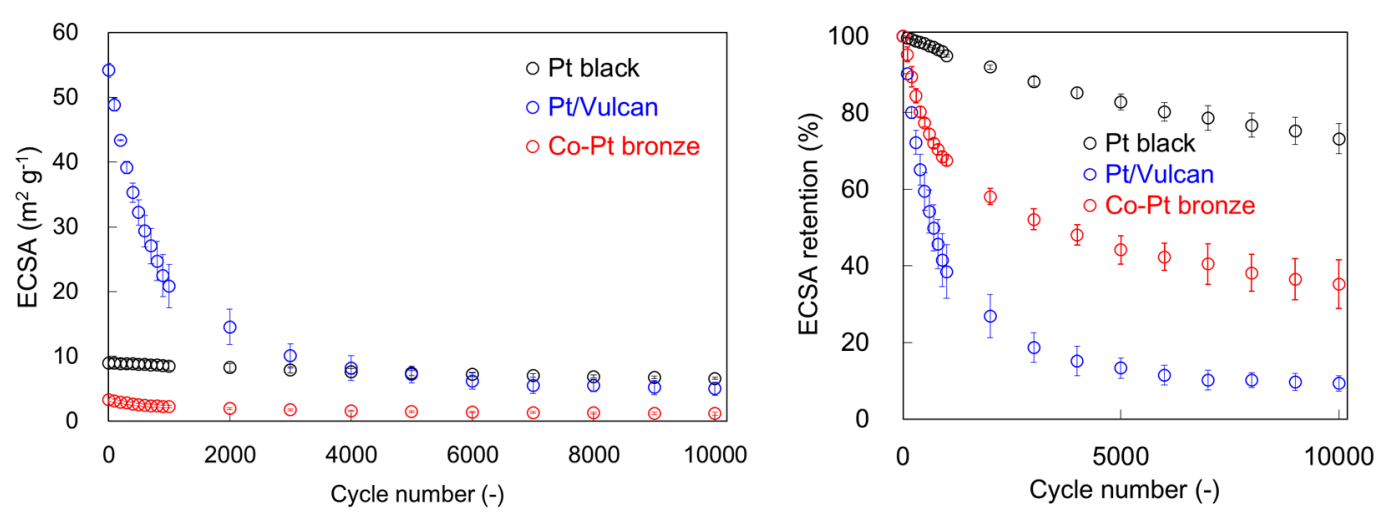

Figure 14. ECSA retention during potential cycle accelerated durability test. 


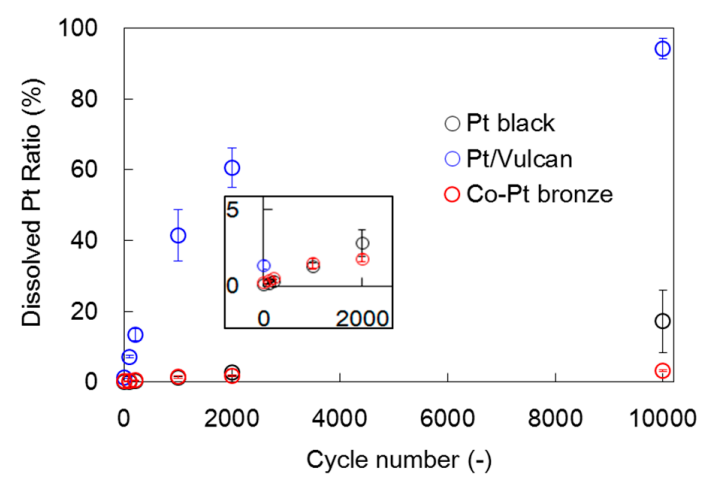

Figure 15. Pt dissolution ratio (=dissolved $\mathrm{Pt} /$ load $\mathrm{Pt}$ on glassy carbon) during potential cycle accelerated durability test. Inserted is an expansion.

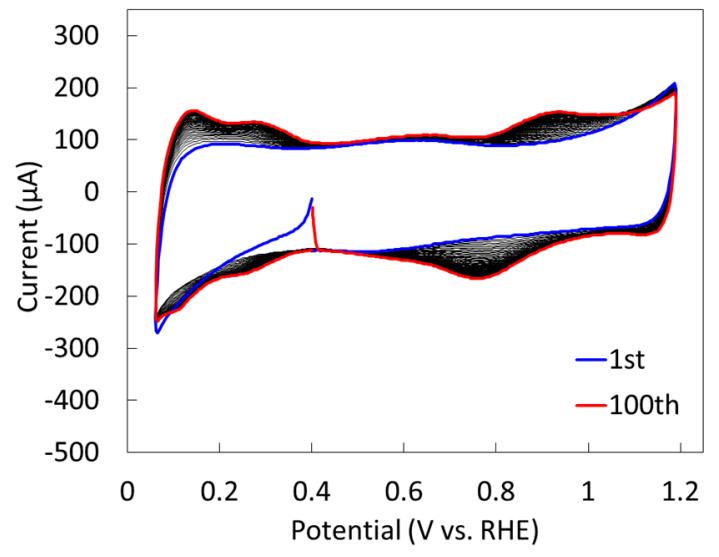

Figure 16. Cyclic Voltammograms during the reactivation potential cycles.

HOR and OER activities of the surface treated Co-Pt bronze were roughly examined by cyclic voltammetry under a hydrogen atmosphere, and the result is shown in Figure 17. Diffusion limiting current was easily achieved for HOR between $0.05 \mathrm{~V}$ and $0.9 \mathrm{~V}$ in the anodic sweep and $0.1 \mathrm{~V}$ and $0.5 \mathrm{~V}$ in the cathodic sweep. A sharp decrease in HOR current toward $0 \mathrm{~V}$ suggests its activity toward HER. These HOR and HER activities are reasonable, since metallic $\mathrm{Pt}$ is formed in this potential range. Depression of HOR current above these potential range is most likely due to platinum oxide formation observed on Pt/C [25]. Above 1.5 V, similar OER current with untreated Co-Pt bronze was observed. This OER activity is due to the native activity of Co-Pt bronze shown in Figure 5.

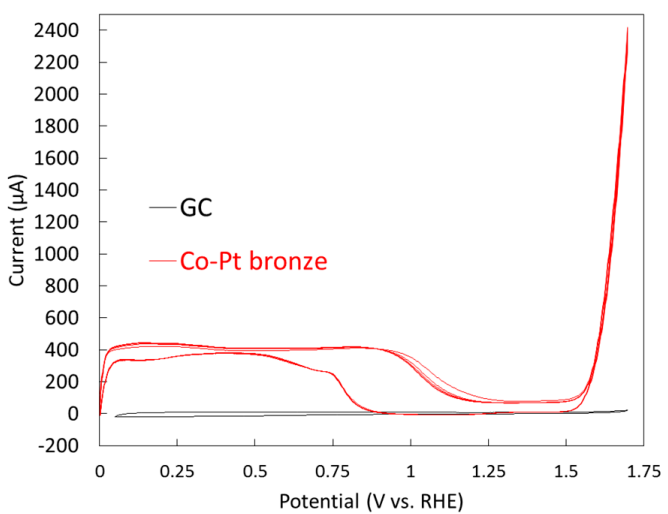

Figure 17. Cyclic Voltammogram of activated Co-Pt bronze showing its HOR and OER activities. 


\section{Experimental}

\subsection{Materials}

Purchased platinum oxide ( $\mathrm{PtO}_{2}$, Sigma-Aldrich, St. Louis, MI, USA, \#459525) and cobalt (II) nitrate hexahydrate $\left(\mathrm{Co}\left(\mathrm{NO}_{3}\right)_{2} \cdot 6 \mathrm{H}_{2} \mathrm{O}\right.$, Kishida Chemical GR, Osaka, Japan, \#000-17605) were used without further purification. Aqua regia was prepared just before its use by mixing $30 \mathrm{~mL}$ of $35 \%$ hydrochloric acid ( $\mathrm{HCl}$, Kishida Chemical GR, \#000-37585) and $10 \mathrm{~mL}$ of $60 \%$ nitric acid $\left(\mathrm{HNO}_{3}\right.$, Kishida Chemical GR, \# 000-54485). $0.1 \mathrm{M} \mathrm{HClO}_{4}$ electrolyte was prepared with $60 \%$ perchloric acid $\left(\mathrm{HClO}_{4}\right.$, Kanto Chemical Ultrapur, Tokyo, Japan, \# 32059-1B) and ultrapure water (Milli-Q. commercial platinum/carbon (Vulcan XC-72) catalyst (TEC10V30E, Tanaka Kikinzoku Kogyo K. K., Tokyo, Japan), Pt black (Pt: \# 685453, Sigma-Aldrich) and two iridium oxides $\left(\mathrm{IrO}_{2}\right.$ : Fine powder, Furuya Metal Co., and \#43396 Iridium(IV) oxide, Premion ${ }^{\circledR}$, Alfa Aesar, Haverhill, MA, USA, Lot\#: N068010) were purchased and used without further treatment. The XRD patterns of the two iridium oxides are shown in Figure S1. While the XRD pattern of $\mathrm{IrO}_{2}$ (Furuya, Tokyo, Japan) agrees well with that of $\mathrm{IrO}_{2}$ crystal, $\mathrm{IrO}_{2}$ (Alfa Aesar) shows significantly-broad peaks roughly agreeing with $\mathrm{IrO}_{2}$ crystal and sharp peaks agreeing with Ir metal. Therefore, it turned out that $\mathrm{IrO}_{2}$ (Furuya) is indeed crystalline $\mathrm{IrO}_{2}$, while $\mathrm{IrO}_{2}$ (Alfa Aesar) is actually a mixture of iridium metal crystal and less-crystalline iridium oxide.

\subsection{Synthesis}

Platinum oxide $(3.952 \mathrm{~g})$ and cobalt (II) nitrate hexahydrate $(1.640 \mathrm{~g})(\mathrm{Pt}: \mathrm{Co}=3: 1 \mathrm{~mol})$ was mixed using a pestle and mortar, and the mixture was heated in an alumina boat placed in an atmosphere-controlled tube at $650{ }^{\circ} \mathrm{C}$ under air stream for $5 \mathrm{~h}$, according to a past study [15]. The obtained powder $(3.536 \mathrm{~g})$ was immersed in hot $\left(80^{\circ} \mathrm{C}\right)$ aqua regia for $30 \mathrm{~min}$ and filtrated to remove soluble components. This cleaning process was carried out three times before it was thoroughly rinsed with ultrapure water (Milli-Q). Cobalt-platinum bronze powder $(1.20 \mathrm{~g})$ was recovered. The recovery was poor because a significant part of the powder attached to the filter could not be retrieved.

\subsection{Characterization}

TEM (transmission electron microscope) observation and EDS (energy dispersive spectroscopy) characterization were carried out with JEOL JEM-2100F (Tokyo, Japan) and FEI Titan G2 60-300 (Columbus, OH, USA). Intense element mapping under high magnitude and elemental point analysis were not carried out because the strong electron beam used for those analyses was found to induce reduction reactions of the bronze, and to change the composition and shape during the analysis. SEM observation was carried out with Hitachi S5500 (Hitachi High-Technologies Corporation, Tokyo, Japan). XRD (X-ray diffractometry) was carried out with Rigaku Ultima IV (Rigaku Corporation, Tokyo, Japan) and the data were analyzed based on the ICDD database. XPS (X-ray photoelectron spectroscopy) was conducted with ULVAC PHI Quantera SXM (Kanagawa, Japan). Electric conductivities of powder samples were measured with a compression cell shown in Figure 18 that allows to apply a controlled pressure to the powder samples [24]. Brunauer-Emmett-Teller (BET) surface area was determined by Quantachrome Autosorb-1 (Boynton Beach, FL, USA). 


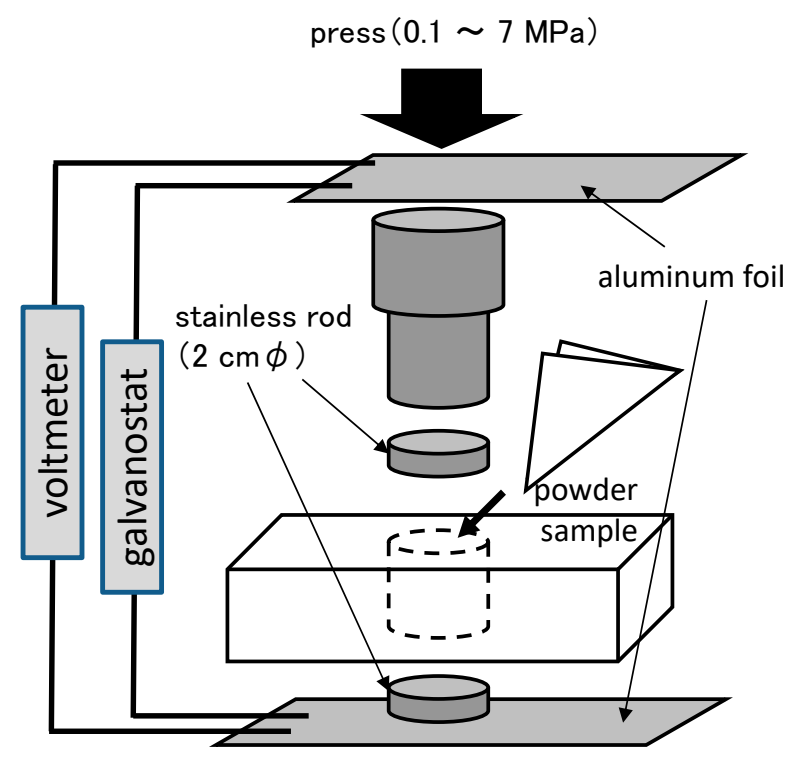

Figure 18. Schematic diagram of a compression cell for measuring conductivity of powder samples.

\subsection{Electrochemical Tests}

Obtained Co-Pt bronze powder was deposited on a glassy carbon (GC) electrode $\left(0.246 \mathrm{~cm}^{2}\right)$ from a dispersion in acetone (100\%) to form a thin film of the bronze containing $13 \mu \mathrm{gcm}^{-2}$ of platinum (assumed $\mathrm{Co}_{0.5} \mathrm{Pt}_{3} \mathrm{O}_{4}$ ). For ORR and HOR activity comparison, a commercial platinum/carbon (Vulcan XC-72) catalyst (TEC10V30E) was deposited on GC similarly. For OER activity comparison, Pt black and two iridium oxides were also deposited on GC. The electrochemical tests were conducted in the rotating disk electrode set-up in $0.1 \mathrm{M} \mathrm{HClO}_{4}$ electrolyte. The detailed electrochemical conditions are described in Table S1.

OER test was conducted by cyclic voltammetry and chronoamperometry whose detailed conditions are listed in Table S2.

ORR test procedures shown in Table S3 are similar with the one described elsewhere [26]. To avoid the reduction of the surface of the bronze from oxide to metal, the electrode potential was held over $0.6 \mathrm{~V}$ at the first stage. Then, the potential was cycled between 0.05 and $1.2 \mathrm{~V}$ before re-examining the ORR activity. An accelerated durability test (ADT) was carried out in a chloride-containing electrolyte by a procedure described in Table S4. Dissolved $\mathrm{Pt}$ ion concentration was determined by stripping voltammetry on a hanging mercury drop electrode [27-29], as shown in Table S5. HOR examination was also carried out by cyclic voltammetry (CV) under a hydrogen atmosphere, and an OER test was conducted by $\mathrm{CV}$ and potential holding conditions under an argon atmosphere.

\section{Conclusions}

An electron-conducting mixed oxide, Co-Pt bronze, was synthesized by a solid state reaction and hot aqua regia treatment. The obtained $20-50 \mathrm{~nm}$ size particles showed high conductivity, high OER, and low ORR activities. Although the OER activity was lower than those of two commercial iridium oxides, its electrochemical stability seemed extremely high, since Co-Pt bronze was electrochemically inert in the potential of interest for OER. Potential cycles to the hydrogen region promoted the formation of thin Pt metallic films on the bronze surface, which is highly active to ORR, HOR, and HER. ADT did not totally dissolve the activated Co-Pt bronze, unlike Pt metal catalysts, and reactivation was possible by additional potential cycles. These unique features can be advantageously utilized for:

- Water electrolyzer anode with high OER activity without Ir or Ru,

- $\quad$ PEFC cathode catalyst with high load-cycle durability and high start-up shutdown durability due to the high OER activity [7], 
- PEFC anode catalyst with high potential-reversal durability due to the high OER activity [7],

- Regenerative fuel cell oxygen-side catalyst.

Remaining issues include:

- Examining long time durability as a water electrolyzer anode,

- Synthesizing smaller particles to improve the mass-activity,

- $\quad$ Synthesizing and testing other metal-platinum bronzes rather than Co-Pt bronze.

Further studies for these issues is expected to expand the possibility of this new class of versatile catalysts.

Supplementary Materials: The following are available online at http:/ www.mdpi.com/2073-4344/8/7/258/s1, Table S1: Experimental set-ups for ORR test and accelerated durability test, Table S2: Experimental procedures for ORR test, Table S3: Experimental procedures for accelerated durability test, Table S4: Pt ion concentration determination, Figure S1: XRD patterns of two commercial iridium oxides, Figure S2: Stripping voltammogram for Pt concentration determination, Figure S3: Calibration line for Pt concentration determination using the peak current at $-0.83 \mathrm{~V}$, Figure S4: TEM image of Co-Pt bronze after ADT.

Author Contributions: Y.K. and Y.M. conceived and designed the experiments; Y.K. performed the experiments and analyzed the data; N.T. performed TEM and EDS analyses; Y.M. wrote the paper.

Funding: The founding sponsors had no role in the design of the study; in the collection, analyses, or interpretation of data; in the writing of the manuscript, and in the decision to publish the results.

Acknowledgments: This study is financially supported by New Energy and Industrial Technology Development Organization. Authors are deeply grateful for kind support by T. Ioroi of The National Institute of Advanced Industrial Science and Technology.

Conflicts of Interest: The authors declare no conflict of interest.

\section{References}

1. Gasteiger, H.A.; Kocha, S.S.; Sompalli, B.; Wagner, F.T. Activity benchmarks and requirements for Pt, Pt-alloy, and non-Pt oxygen reduction catalysts for PEMFCs. Appl. Catal. B Environ. 2005, 56, 9-35. [CrossRef]

2. Adzic, R.R.; Zhang, J.; Sasaki, K.; Vukmirovic, M.B.; Shao, M.; Wang, J.X.; Nilekar, A.U.; Mavrikakis, M.; Valerio, J.A.; Uribe, F. Platinum monolayer fuel cell electrocatalysts. Top. Catal. 2007, 46, 249-262. [CrossRef]

3. Chung, D.Y.; Jun, S.W.; Yoon, G.; Kwon, S.G.; Shin, D.Y.; Seo, P.; Yoo, J.M.; Shin, H.; Chung, Y.H.; Kim, H.; et al. Highly Durable and Active PtFe Nanocatalyst for Electrochemical Oxygen Reduction Reaction. J. Am. Chem. Soc. 2015, 137, 15478-15485. [CrossRef] [PubMed]

4. Choi, S.I.; Xie, S.F.; Shao, M.H.; Odell, J.H.; Lu, N.; Peng, H.C.; Protsailo, L.; Guerrero, S.; Park, J.H.; Xia, X.H.; et al. Synthesis and Characterization of $9 \mathrm{~nm}$ Pt-Ni Octahedra with a Record High Activity of $3.3 \mathrm{~A} / \mathrm{mg}(\mathrm{Pt})$ for the Oxygen Reduction Reaction. Nano Lett. 2013, 13, 3420-3425. [CrossRef] [PubMed]

5. Pivovar, B. Extended, Continuous PtNanostructures in Thick, Dispersed Electrodes; 2015 Annual Merit Review; DOE: Washington, DC, USA, 2015; p. 8.

6. Meyers, J.P.; Darling, R.M. Model of Carbon Corrosion in PEM Fuel Cells. J. Electrochem. Soc. 2006, 153, A1432-A1442. [CrossRef]

7. Gallagher, K.G.; Darling, R.M.; Fuller, T.F. Carbon-support corrosion mechanisms and models. In Handbook of Fuel Cells; John Wiley \& Sons, Ltd.: Hoboken, NJ, USA, 2010; Volume 6, pp. 819-828.

8. Han, L.; Dong, S.; Wang, E. Transition-Metal (Co, Ni, and Fe)-Based Electrocatalysts for the Water Oxidation Reaction. Adv. Mater. 2016, 28, 9266-9291. [CrossRef] [PubMed]

9. Reier, T.; Nong, H.N.; Teschner, D.; Schlögl, R.; Strasser, P. Electrocatalytic Oxygen Evolution Reaction in Acidic Environments-Reaction Mechanisms and Catalysts. Adv. Energy Mater. 2017, 7, 1601275. [CrossRef]

10. Alia, S.M.; Shulda, S.; Ngo, C.; Pylypenko, S.; Pivovar, B.S. Iridium-Based Nanowires as Highly Active, Oxygen Evolution Reaction Electrocatalysts. ACS Catal. 2018, 8, 2111-2120. [CrossRef]

11. Alia, S.M.; Rasimick, B.; Ngo, C.; Neyerlin, K.C.; Kocha, S.S.; Pylypenko, S.; Xu, H.; Pivovar, B.S. Activity and Durability of Iridium Nanoparticles in the Oxygen Evolution Reaction. J. Electrochem. Soc. 2016, 163, F3105-F3112. [CrossRef] 
12. Cherevko, S.; Geiger, S.; Kasian, O.; Kulyk, N.; Grote, J.-P.; Savan, A.; Shrestha, B.R.; Merzlikin, S.; Breitbach, B.; Ludwig, A.; et al. Oxygen and hydrogen evolution reactions on $\mathrm{Ru}, \mathrm{RuO}_{2}$, $\mathrm{Ir}$, and $\mathrm{IrO}_{2}$ thin film electrodes in acidic and alkaline electrolytes: A comparative study on activity and stability. Catal. Today 2016, 262, 170-180. [CrossRef]

13. Rudnick, R.L.; Gao, S. 3.01-Composition of the Continental Crust A2-Holland, Heinrich D. In Treatise on Geochemistry; Turekian, K.K., Ed.; Pergamon: Oxford, UK, 2003; pp. 1-64.

14. Park, S.; Shao, Y.; Liu, J.; Wang, Y. Oxygen electrocatalysts for water electrolyzers and reversible fuel cells: Status and perspective. Energy Environ. Sci. 2012, 5, 9331-9344. [CrossRef]

15. Shannon, R.D.; Gier, T.E.; Carcia, P.F.; Bierstedt, P.E.; Flippen, R.B.; Vega, A.J. Synthesis and properties of platinum metal-oxides of the type $\mathrm{MXPT}_{3} \mathrm{O}_{4}$. Inorg. Chem. 1982, 21, 3372-3382. [CrossRef]

16. Schwartz, K.B.; Parise, J.B.; Prewitt, C.T.; Shannon, R.D. Analysis of structural distortions in nonstoichiometric ternary platinum oxides- $\mathrm{Li} 0.64 \mathrm{Pt}_{3} \mathrm{O}_{4}$ and $\mathrm{Co} 0.37 \mathrm{Na} 0.14 \mathrm{Pt}_{3} \mathrm{O}_{4}$. Acta Crystallogr. Sect. B Struct. Sci. 1982, 38, 2109-2116. [CrossRef]

17. Swette, L.; Kackley, N.; McCatty, S.A. Oxygen electrodes for rechargeable alkaline fuel cells. III. J. Power Sources 1991, 36, 323-339. [CrossRef]

18. Swette, L.; Kackley, N. Oxygen electrodes for rechargeable alkaline fuel cells-II. J. Power Sources 1990, 29, 423-436. [CrossRef]

19. Schwartz, K.B.; Prewitt, C.T. Structural and electronic-properties of binary and ternary platinum oxides. J. Phys. Chem. Solids 1984, 45, 1-21. [CrossRef]

20. Tryk, D.A.; Zhang, Z.; Aldred, W.H.; Kim, S.; Scherson, D.A.; Yeager, E.B. Nickel-Platinum Bronzes as Electrocatalysts for Oxygen Reduction in Acid Electrolytes. In Proceedings of the Symposium on Electrode Materials and Processes for Energy Conversion and Storage, Pennington, NJ, USA, 1994; Supramaniam Srinivasan, D.D.M., Khandkar, A.C., Eds.; Electrochemical Society: Pennington, NJ, USA, 1994.

21. Marković, N.M.; Schmidt, T.J.; Stamenković, V.; Ross, P.N. Oxygen Reduction Reaction on Pt and Pt Bimetallic Surfaces: A Selective Review. Fuel Cells 2001, 1, 105-116. [CrossRef]

22. Anderson, A.B.; Roques, J.; Mukerjee, S.; Murthi, V.S.; Markovic, N.M.; Stamenkovic, V. Activation Energies for Oxygen Reduction on Platinum Alloys: Theory and Experiment. J. Phys. Chem. B 2005, 109, 1198-1203. [CrossRef] [PubMed]

23. Choi, S.I.; Choi, R.; Han, S.W.; Park, J.T. Shape-Controlled Synthesis of Pt3Co Nanocrystals with High Electrocatalytic Activity toward Oxygen Reduction. Chem. Eur. J. 2011, 17, 12280-12284. [CrossRef] [PubMed]

24. Pantea, D.; Darmstadt, H.; Kaliaguine, S.; Sümmchen, L.; Roy, C. Electrical conductivity of thermal carbon blacks: Influence of surface chemistry. Carbon 2001, 39, 1147-1158. [CrossRef]

25. Zalitis, C.M.; Sharman, J.; Wright, E.; Kucernak, A.R. Properties of the hydrogen oxidation reaction on Pt/C catalysts at optimised high mass transport conditions and its relevance to the anode reaction in PEFCs and cathode reactions in electrolysers. Electrochim. Acta 2015, 176, 763-776. [CrossRef]

26. Shinozaki, K.; Zack, J.W.; Richards, R.M.; Pivovar, B.S.; Kocha, S.S. Oxygen reduction reaction measurements on platinum electrocatalysts utilizing rotating disk electrode technique I. Impact of impurities, measurement protocols and applied corrections. J. Electrochem. Soc. 2015, 162, F1144-F1158. [CrossRef]

27. Obata, H.; Yoshida, T.; Ogawa, H. Determination of picomolar levels of platinum in estuarine waters: A comparison of cathodic stripping voltammetry and isotope dilution-inductively coupled plasma mass spectrometry. Anal. Chim. Acta 2006, 580, 32-38. [CrossRef] [PubMed]

28. Wang, J.; Zadeii, J.; Lin, M.S. Ultrasensitive voltammetric measurements based on coupling hydrogen catalytic systems with controlled interfacial accumulation of the catalyst. J. Electroanal. Chem. Interfacial Electrochem. 1987, 237, 281-287. [CrossRef]

29. Zhao, Z.; Freiser, H. Differential pulse polarographic determination of trace levels of platinum. Anal. Chem. 1986, 58, 1498-1501. [CrossRef]

(c) 2018 by the authors. Licensee MDPI, Basel, Switzerland. This article is an open access article distributed under the terms and conditions of the Creative Commons Attribution (CC BY) license (http:/ / creativecommons.org/licenses/by/4.0/). 